\title{
General Editors' Foreword
}

The Florence Integration Through Law Series is the product of a research project centered in the Law Department of the European University Institute, and as such it reflects the research interests of the Department: it is a contextual examination of European legal developments in comparative perspective. In the general introduction to the Series (published in Book One of Volume I), we explained fully the philosophy, methodology and scope of the Project. Here we wish merely to recapitulate some of the principal themes of special relevance to this Volume on Environmental Protection.

The European Legal Integration Project set out to examine the role of law in, and the legal impact of, integration in Europe, using the United States federal system as a comparative point of reference. The Project was conceived and executed in two parts. In Part One (published in Volume I entitled "Methods, Tools and Institutions") a number of teams of American and European scholars examined a wide range of legal techniques and mechanisms for integration and undertook an overall general analysis of law and integration. The first book of Volume I ("A Political, Legal, and Economic Overview") establishes the comparative and interdisciplinary context, providing background studies on the political, legal and economic implications of integration in $\mathrm{Eu}$ rope and America and including studies on other federal systems (Australia, Canada, Germany and Switzerland) to add comparative perspective. The second book ("Political Organs, Integration Techniques, and Judicial Process") analyzes the pre- and post-normative stages, examining the decision-making and implementation problems, and the role of political and judicial organs therein, and describing the various forms of normative techniques available in a federal or supranational context.

The third and final book of Volume I ("Forces and Potential for a European Identity") focusses on how the law can be harnessed to promote the governmental or integrational objectives of union. It isolates for consideration some substantive goals (foreign policy, free movement of goods and persons, human rights protection and legal education), in order to elucidate the ways in which law has been or can be used to promote substantive objectives. This approach is more fully developed in the studies in Part Two of the Project which deals in greater detail with substantive areas of federal/transnational policy an is open-ended. To date, in addition to the present volume on environmental policy, monographs have been planned in the following four areas: consumer protection, harmonization of corporation law and capital markets, energy policy, and regional policy. It is hoped that further studies may be undertaken in the future.

One may ask how our choices were made. Why should environmental pro- 
tection be selected as the first substantive study in a project dealing with European integration in a comparative context? There is more than one explanation.

In the first place we tried to concentrate on areas which may be regarded as second or even third generation Community policies. Environmental policy is not explicitly envisaged in the Treaties; indeed there existed a serious legal problem as regards the competence of the Communities to enter this field. But it is a typical example of the kind of policy which has emerged on the foundations of the classical common market and which is a result of, and a condition for, the market's successful operation and evolution. More specifically, it is a policy which represents the operation of the "positive state" in the mixed economy. It is thus far more representative of current exigencies than the first generation policies - of the "negative" kind which simply required the states to eliminate certain practices. It typifies the kind of challenge which the process of European integration will increasingly face.

The inclusion of environmental protection as the first of the substantive studies had another attraction. It represents, alongside consumer protection which is the subject of another study in this part of the Project, the need for the Community to spread into new areas of social relevance. In some ways these areas could be seen as policies enhancing the Common Market: equalizing competition, harmonizing regulations so as to remove barriers to trade and so forth. But they also represent a social challenge in their own right. It is fashionable today to dismiss the protection of the consumer or the environment as a luxury, or indeed a fad, of the 1960's, a characteristic of economic growth and ample resources (though the steady destruction of European age-old forests by "transnational" acid rain has provided a new urgency to the environmental issue). But in our view, this, and similar social activity by the Community, is essential if Europe is really to progress into a social rather than merely legal and economic reality.

Finally, there is another, less "rational," reason for presenting this study first. It is common today to feel gloomy about the future of European integration. Much in this Project highlights the reasons, frequently justified, for such gloom. But European environmental protection is a story of some success and future hope. The ecological challenge in many of its dimensions does not recognize national boundaries. It is a classical area for transnational cooperation. Measured against the challenge it might seem that very little has been done; the limited success is dwarfed by the environmental hazards. But, nonetheless, the study illustrates that given even a limited amount of political will, the European transnational level offers possibilities for tackling problems which could not otherwise be easily confronted.

Environmental law as a topic for legal analysis has, of course, already elicited a substantial amount of scholarly attention. Why then present this new examination? First and foremost is the value of a fresh analysis by the distinguished authors of this volume. But in addition, it is our belief that the Integration Project provided a special context for specific and unique insights. Most obvious is the comparative context: this study presents a tight comparative 
analysis of the European and American experiences. Through this comparative analysis we gain a better understanding of the problems associated with, for example, cross-frontier control of environmental hazards; we also gain a better understanding of the workings of the transnational/federal system of governance. There is as much to be learnt from this volume on the process of integration and its problems as there is to be learnt on the legal dimensions of environmental protection.

The Project has invited, however, more than the comparative contribution. The Florence Integration Through Law Series is dedicated to the concept of Law in Context: the examination of legal problems in their political, economic and social setting. There has been much pontification in recent years about the value of interdisciplinarity. Implementation of this value, however, often falls short of much hallowed theoretical expectations. In this regard our claims were modest; we did not ask our contributors to bring the full scientific paraphernalia of, say economics or political science to bear on their subject. We simply asked that the legal analysis be situated in, and be sensitive to, the implications of the socio-economic and political context. The present volume is, in our view, an extraordinarily successful example of this approach.

The European Integration Project follows on from an earlier wide-ranging research project which was carried out at the European University Institute - the Florence Access-to-Justice Project. Access to Justice was not only concerned with an examination and, indeed, extension of the procedural and institutional mechanisms for the vindication of rights in contemporary society. It was an approach which sought to emphasize that in legal study, an analysis of the normative content of legal rules and policies - while still central - can give only a partial picture of the function and shortcomings of the law in its societal context. Normative analysis is but one layer of analysis: the effective (or otherwise) reach of the law, its implementation and enforcement, its accessibility to subjects to whom it is addressed as a source of rights and duties, is a second no less important layer. This approach has been a constant guideline to all contributions to the European Integration Project.

Problems of implementation and enforcement are notorious in the field of environmental protection. They are aggravated in the European transnational system which has its own inherent difficulties of supervision and compliance. This study deals in depth with this dimension, and is one of the first of its kind in the European context. Moreover, it is not only in highlighting implementation problems existent at the time of writing that the study makes a contribution. Its overriding value in this connection is in providing an analytical framework for examining the problem in general, a framework which will have a value well beyond the identification of concrete issues at any given point in time.

If the Access-to-Justice philosophy postulated the addition of this post-normative layer in the analysis of law, the institutional and procedural character of the Integration Project postulated the addition of yet another layer - a pre-normative layer. Both in the first general methodological part of the Project and in its second substantive part we have given considerable attention to 
the decision-making process by and through which norms emerge. The necessity of this addition is so clear as to obviate any lengthy explanation. Not only is decision-making an essential component in the analysis of the system as a whole, but it also gives, particularly in the context of the European transnational concordance of interests, an insight into the normative outcome and, as explained throughout the Project, into the very problems of implementation, application and enforcement. The study on the environment, as well as other studies in Part Two of the Project, has adopted what one may call a "total" approach to legal analysis. Certainly the normative, "black letter" dimension of the law is explored; but this normative analysis is sandwiched between the preand post-normative phase. The volume explores fully the process of policy-making, the difficulty it encounters and the political context against which normative compromises are reached.

The Integration Through Law Series represents a collective effort over a long period of time. At its inception we believed that the first methodological part of the Project would be the setting against which the subsequent substantive parts, such as this study on environmental protection policy, would be written. Things often do not turn out as they were planned. The two parts of the Project in fact evolved simultaneously, and while the Part Two studies undoubtedly did rely on the general methodological background studies of Part One, the studies in Part One equally drew upon the analysis contained in the concrete substantive studies of Part Two. In this process of cross-fertilization Professors Rehbinder and Stewart played a key role. Their insight into the evolution and problems of federalism and integration informed and enhanced much of the rest of our work. Their level of dedication and scholarship set a standard for the entire Project. Their collegiality and cooperation with the editors significantly facilitated our tasks. We are truly grateful to them.

Florence, December 1984

Mauro Cappelletti Monica Seccombe Joseph Weiler 